\title{
Validity and feasibility of a learning style instrument for brain injury rehabilitation
}

Citation for published version (APA):

Boosman, H., van Heugten, C. M., Post, M. W. M., Lindeman, E., \& Visser-Meily, J. M. A. (2013). Validity and feasibility of a learning style instrument for brain injury rehabilitation. Disability and Rehabilitation, 35(21), 1783-1789. https://doi.org/10.3109/09638288.2012.753117

Document status and date:

Published: 01/01/2013

DOI:

10.3109/09638288.2012.753117

Document Version:

Publisher's PDF, also known as Version of record

Document license:

Taverne

Please check the document version of this publication:

- A submitted manuscript is the version of the article upon submission and before peer-review. There can be important differences between the submitted version and the official published version of record.

People interested in the research are advised to contact the author for the final version of the publication, or visit the DOI to the publisher's website.

- The final author version and the galley proof are versions of the publication after peer review.

- The final published version features the final layout of the paper including the volume, issue and page numbers.

Link to publication

\footnotetext{
General rights rights.

- You may freely distribute the URL identifying the publication in the public portal. please follow below link for the End User Agreement:

www.umlib.nl/taverne-license

Take down policy

If you believe that this document breaches copyright please contact us at:

repository@maastrichtuniversity.nl

providing details and we will investigate your claim.
}

Copyright and moral rights for the publications made accessible in the public portal are retained by the authors and/or other copyright owners and it is a condition of accessing publications that users recognise and abide by the legal requirements associated with these

- Users may download and print one copy of any publication from the public portal for the purpose of private study or research.

- You may not further distribute the material or use it for any profit-making activity or commercial gain

If the publication is distributed under the terms of Article $25 \mathrm{fa}$ of the Dutch Copyright Act, indicated by the "Taverne" license above, 


\section{Disability and Rehabilitation}

\section{Validity and feasibility of a learning style instrument for brain injury rehabilitation}

H. Boosman, C. M. van Heugten, M. W. M. Post, E. Lindeman \& J. M. A. VisserMeily

To cite this article: H. Boosman, C. M. van Heugten, M. W. M. Post, E. Lindeman \& J. M. A. Visser-Meily (2013) Validity and feasibility of a learning style instrument for brain injury rehabilitation, Disability and Rehabilitation, 35:21, 1783-1789, DOI: 10.3109/09638288.2012.753117

To link to this article: https://doi.org/10.3109/09638288.2012.753117

曲 Published online: 24 Jan 2013.

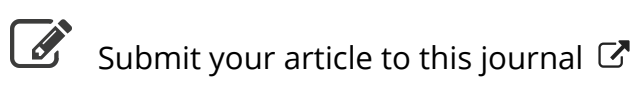

Џll Article views: 257

Q View related articles $\sqsubset$ 


\title{
Validity and feasibility of a learning style instrument for brain injury rehabilitation
}

\author{
H. Boosman ${ }^{1}$, C. M. van Heugten ${ }^{2,3}$, M. W. M. Post ${ }^{1}$, E. Lindeman ${ }^{1}$, and J. M. A. Visser-Meily ${ }^{1}$ \\ ${ }^{7}$ Rudolf Magnus Institute of Neuroscience and Centre of Excellence for Rehabilitation Medicine, University Medical Centre Utrecht and \\ De Hoogstraat Rehabilitation, Utrecht, the Netherlands, ${ }^{2}$ Department of Psychiatry and Neuropsychology, School for Mental Health and \\ Neuroscience, Maastricht University Medical Center (MUMC), Maastricht, the Netherlands, and ${ }^{3}$ Department of Neuropsychology and \\ Psychopharmacology, Maastricht University, Maastricht, the Netherlands
}

\begin{abstract}
Purpose: Identifying learning styles of acquired brain injury ( $\mathrm{ABI}$ ) patients may aid the learning process by tailoring to the patient's learning needs and preferences. Currently, there is no learning style instrument for $A B I$ patients. We therefore determined the validity and feasibility of the Adapted Learning Style Inventory (A-LSI) for patients with ABI. Method: We included 99 patients with $A B I$ and 42 healthy controls. Learning styles were determined and subgroups were used to evaluate the validity of the A-LSI. Furthermore, rehabilitation professionals' perceptions on learning style and the A-LSI were evaluated. Results: In the patient group, the A-LSI yielded the following learning styles: 4 doers, 54 observers, 2 deciders and 39 thinkers. A similar distribution was found for the control group (3, 28, 0 and 11, respectively). Spearman correlations revealed moderate internal validity. Content validity of the A-LSI was also moderate; 11 out of 19 patients recognized themselves in their A-LSI learning style. Furthermore, 12 rehabilitation professionals reported positive and negative aspects of the A-LSI and suggestions for using learning style in rehabilitation. Conclusions: Rehabilitation professionals were generally positive about using learning style in $\mathrm{ABI}$ rehabilitation. This study, however, raises doubts about the validity and feasibility of the A-LSI for this population.
\end{abstract}

\section{> Implications for Rehabilitation}

- Rehabilitation professionals are generally positive about the assessment and implementation of learning style in rehabilitation.

- The A-LSI seems to be an inappropriate learning style instrument for individuals with ABI.

- There is a need for a more practical instrument to assess learning style directly at start of rehabilitation.

\section{Keywords}

Adapted learning style inventory, brain injury, learning style

\section{History}

Received 6 July 2012

Revised 19 November 2012

Accepted 22 November 2012

Published online 24 January 2013

\section{Introduction}

Patients with acquired brain injury (ABI) frequently experience enduring physical and cognitive impairments that require rehabilitation. In rehabilitation, these patients often follow a standard rehabilitation programme in which they relearn old skills and learn new skills in order to optimize social participation and well-being [1]. The fact that learning occupies a central position in the process of rehabilitation indicates the importance of increasing our knowledge about learning and the relevance and

Address for correspondence: J. M. A. Visser-Meily, Rudolf Magnus Institute of Neuroscience and Centre of Excellence for Rehabilitation Medicine, University Medical Centre Utrecht and De Hoogstraat Rehabilitation, PO Box 85500, 3508 GA Utrecht, the Netherlands. Tel: 00318875 58831. Fax: 00318875 55450. E-mail: j.m.a.vissermeily@umcutrecht.nl applicability of educational and didactic concepts in a rehabilitation setting.

There are numerous examples of learning situations in rehabilitation. For instance learning how to walk again, learning how to use compensatory strategies for deficits in memory and attention, or learning how to deal with limitations. There is, however, little knowledge about the way in which patients with ABI most efficiently and effectively learn such skills in rehabilitation. A closely related educational concept, that is currently emerging in the field of rehabilitation, is "learning style", [2]. Learning style is the preferred way in which an individual approaches or chooses a learning situation and is associated with learning results [3]. Some individuals may, for instance, prefer to learn from hands-on experience, whereas others prefer to first think things through and reflect on their observations. The identification and implementation of a patient's learning style can possibly aid the learning process by tailoring to the patient's learning needs and preferences [2]. Recent studies 
have reported positive effects of matching learning style to cognitive-behaviour therapy technique in healthy persons [4] and of learning style tailored education materials in emergency room patients [5].

Although several studies have addressed learning style in patients with ABI [6-10], much remains to be explored. Currently, no specific instrument to assess learning style in this population has been developed. The available learning style measures were developed for educational purposes, for instance within the field of health, management, and academic settings [3]. It is unknown whether these instruments are also feasible and valid for patients with $\mathrm{ABI}$ since they frequently experience impairments regarding language, executive functioning, attention and slowed information processing [11-13]. Moreover, learning style assessment in rehabilitation would only be one of a large variety of measurement instruments that most patients need to complete during rehabilitation. Therefore, an assessment instrument has to be brief and easy to use. Unfortunately, the majority of existing instruments are quite lengthy and therefore less appropriate for use in rehabilitation.

Before developing a learning style instrument specifically for $\mathrm{ABI}$ rehabilitation, we believe it is important to start with evaluating an existing learning style instrument to gain familiarity and experience with learning style in rehabilitation. To this end, an existing learning style instrument, the Adapted Learning Style Inventory (A-LSI) [14], was implemented. The A-LSI is based on Kolb's experiential learning theory (ELT) [15]. According to the ELT, effective learning is a continuous and interactive process depending on four learning modes, reflected by the four scales of the A-LSI: (1) concrete experience (CE) - doing something and discover its consequences; (2) reflective observation (RO) - watch what happens and think about it; (3) abstract conceptualization (AC) - talk with others and apply existing knowledge and (4) active experimentation (AE) - test theories and carry out plans. These four learning modes can be used to calculate two independent bipolar dimensions of learning: prehension ( $\mathrm{AC}$ minus $\mathrm{CE}$ ) and transformation (AE minus RO). Prehension is the act of grasping information from experience (abstract versus concrete) and transformation is the processing of this information (active versus reflective). The two dimensions are bipolar since it is, for example, impossible to simultaneously analyse the manual of an electric wheelchair (abstract) and drive the electric wheelchair (concrete) [16].

The objectives of this exploratory study were (1) to determine the distribution of learning styles in patients with $\mathrm{ABI}$ and healthy controls; (2) to evaluate the validity of the A-LSI in patients with $\mathrm{ABI}$ and (3) to evaluate rehabilitation professionals' perceptions on the A-LSI and learning style in general.

\section{Methods}

\section{Participants}

For this chart review study, we considered files of adult patients with ABI consecutively referred to inpatient rehabilitation at De Hoogstraat Rehabilitation (the Netherlands) between January 2008 and January 2011. At De Hoogstraat Rehabilitation, all patients are informed that their files can be used anonymously for research purposes, unless they object. The study was conducted according to the Code of Conduct for Medical Research of the Council of the Dutch Federation of Medical Scientific Societies. Since this study was based on secondary use of data, a review procedure by a medical ethics committee was not needed.

We included patients with ABI who completed the A-LSI as part of a routine assessment at the start of cognitive rehabilitation. Since the A-LSI is a written questionnaire, patients with severe aphasia or insufficient command of the Dutch language, were not assessed.

A control group was recruited as a reference sample for the distribution of learning styles. The controls were volunteers who came to our attention by word of mouth. Inclusion criteria were age above 18, sufficient command of the Dutch language and written informed consent. Controls with cognitive impairments, indicated by a Mini Mental State Examination (MMSE) [17] score below 27, were excluded.

\section{Measures}

Demographic data and ABI characteristics were collected from the files. ADL dependence was assessed using the Barthel Index [18] score at admission to the rehabilitation centre. It has a 0-20 range for which a higher score reflects better functioning. In addition, the cognitive scale of the Utrecht Scale for Evaluation of Rehabilitation (USER) [19] was used to provide an indication of cognitive functioning. The USER is an observational instrument. The cognitive scale has 10 items each with a $0-5$ range for which a higher score indicates better functioning. The total score range is $0-50$.

Learning style was assessed with the A-LSI [14] which is a modified version of Kolb's LSI [15]. In contrast to Kolb's LSI, the A-LSI includes questions about concrete situations such as learning how to sail a boat. The items of Kolb's LSI are stated more generally (e.g. I learn by: doing, watching, thinking and feeling). Therefore, the A-LSI seemed more appropriate for use in ABI rehabilitation than Kolb's LSI. Since the A-LSI was originally developed for college students, items have been slightly changed into age-appropriate questions. See Table A1 (appendix) for an English translation of the Dutch A-LSI.

The A-LSI is based on Kolb's model of experiential learning [15] described above and contains nine items each with four answers corresponding to the four learning modes: $\mathrm{CE}, \mathrm{AC}, \mathrm{AE}$ and RO. Persons were asked to rank the answers by giving 1, 2, 3 and 4 points in which four points represents the most suitable answer and one point the least suitable answer. The items belonging to the same mode are summed. For each mode, three items are not included in the sum-scores which leaves sum scores ranging from 6 to 24. Consequently, two independent bipolar dimensions of learning are calculated: prehension (AC minus $\mathrm{CE}$ ) and transformation (AE minus $\mathrm{RO}$ ). Relative positioning along these two bipolar dimensions defines a preference for one of the following four learning styles: doer, observer, decider or thinker (Figure 1).

\section{Procedure}

The cognition therapist completed and interpreted the A-LSI together with the patient within a one hour session. The amount of assistance given while completing the A-LSI was dependent upon the patient's physical (e.g. fatigue, visual impairments) and cognitive functioning (e.g. neglect, attention deficits). The assistance could consist of, for example, clarifying the individual items, reading the questions aloud or providing more structure by showing the answers one at a time on separate cards. In the case of neglect, a perpendicular vertical line was drawn as a cue to the neglected side. The results were discussed with the patient after approximately one week. Based on the A-LSI result and observations during completion of the test, the cognition therapist wrote a report with individually tailored learning advice for all involved disciplines.

According to the exploratory character of the study, a convenience sample was selected to do an additional task. To assess content validity of the A-LSI, 19 patients and 38 controls 


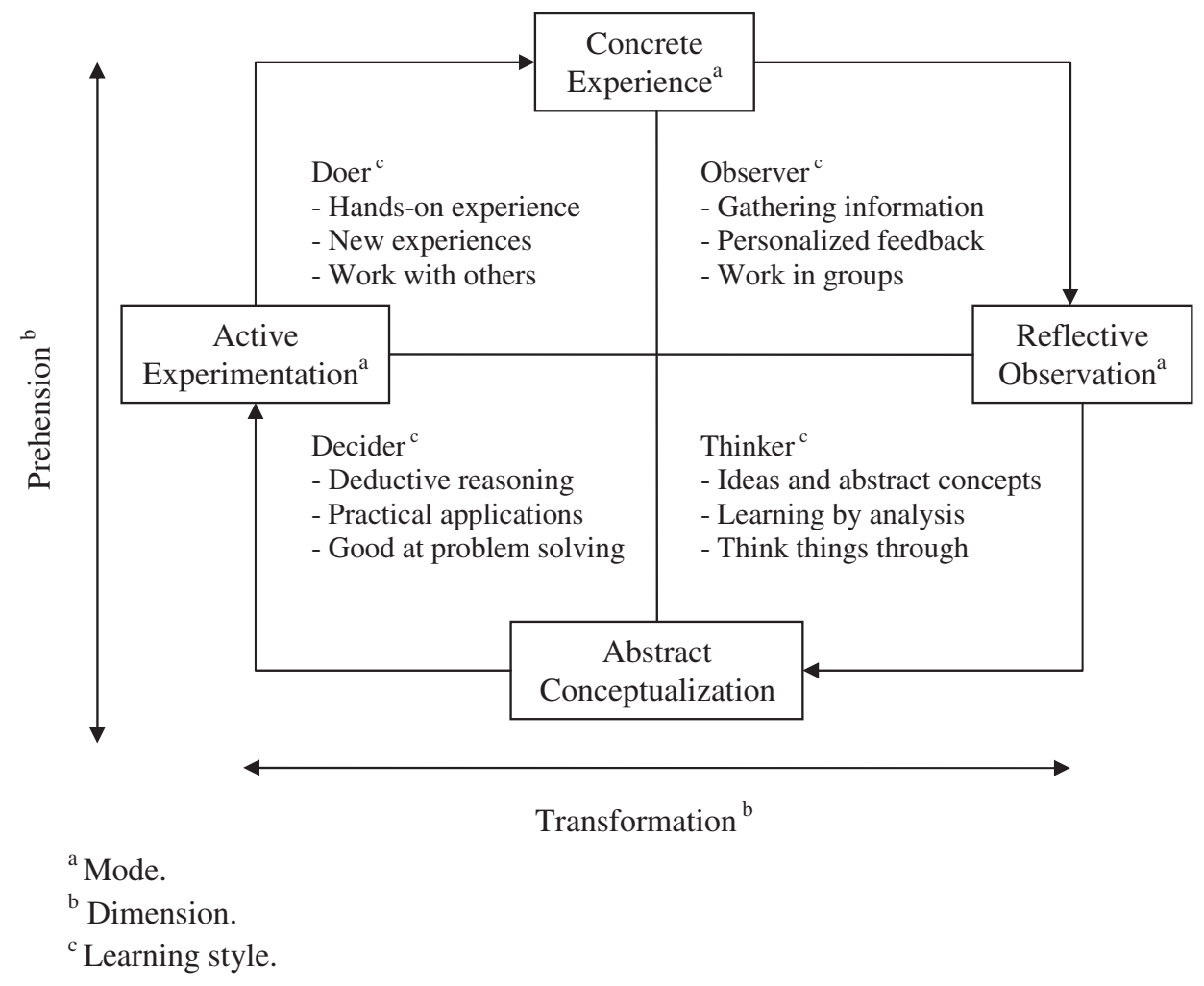

Figure 1. Learning styles and matching learning preferences [18].

were asked whether they recognized themselves in the assessed learning style on a seven-point scale.

The use of learning styles and the A-LSI in patients with ABI was qualitatively evaluated by interviewing three psychologists, three physical therapists, three occupational therapists and three cognition therapists of the rehabilitation teams who were all familiar with the concept of learning style. All interviewees have acquired basic knowledge of learning style through a one-day workshop at the rehabilitation centre. We asked them about the use of learning style in clinical practice, positive and negative aspects of the A-LSI, and potential suggestions for improvement.

\section{Statistical analysis}

Learning style distributions were described for the patient group and the control group using descriptive statistics. Non-parametric statistics (Mann-Whitney $U$-test and Chi squared test) were applied to determine differences between the patients and controls regarding gender, age, education, learning style and recognition of the assessed learning style. Furthermore, a Chi squared test was used to determine whether there was an association between learning style and education.

Internal validity of the A-LSI was determined by calculating spearman correlations between learning modes and dimensions [15]. The following hypotheses were formulated to test the presence of two independent bipolar dimensions:

(1) The two dimensions, prehension $(\mathrm{AC}-\mathrm{CE})$ and transformation $(\mathrm{AE}-\mathrm{RO})$, are independent:

(a) No significant association between the two dimensions.

(b) No significant association between the learning modes $\mathrm{CE}$ and $\mathrm{AC}$ and the dimension $\mathrm{AE}-\mathrm{RO}$.

(c) No significant association between the learning modes $\mathrm{AE}$ and $\mathrm{RO}$ and the dimension $\mathrm{AC}-\mathrm{CE}$.

(d) The two dimensions are bipolar:

(e) A significant negative association for the within-dimension learning modes ( $\mathrm{AC}$ and $\mathrm{CE} ; \mathrm{AE}$ and $\mathrm{RO}$ ). (f) The correlations between the cross-dimensional learning modes ( $\mathrm{CE}$ and $\mathrm{RO}$; $\mathrm{AC}$ and $\mathrm{AE}$; $\mathrm{CE}$ and $\mathrm{AE}$; and $\mathrm{AC}$ and $\mathrm{RO})$ are lower than the within-dimension learning modes (AC and $\mathrm{CE}$; $\mathrm{AE}$ and $\mathrm{RO}$ ).

Content validity of the A-LSI was determined by asking patients and controls whether they recognized themselves in the assessed learning style. The score ranged from 1 (strongly disagree) to 7 (strongly agree). Scores exceeding 5 were considered a positive recognition.

Data were analysed using SPSS version 18.0, $p$ value was set at 0.05. In the case of multiple comparisons, a Bonferroni correction was applied.

\section{Results}

\section{Participants}

In total, 99 patients with $\mathrm{ABI}$ and 42 healthy controls were included in this study. The majority of patients suffered a stroke (77.8\%, $n=77)$. At admission to the rehabilitation centre, the mean Barthel Index score was 14.8 (SD 4.9). In total, 58.5\% $(n=58)$ of patients were ADL independent or mildly disabled and $41.4 \%$ were moderately to severely ADL disabled. The cognitive scale of the USER yielded a mean score of 40.1 (SD 8.9). The mean time between admission to the rehabilitation centre and administration of the A-LSI was 41.1 days (SD 40.9). Table 1 presents the sample characteristics.

A Mann-Whitney $U$-test revealed no significant difference in age of the patients and controls $(U=1859.0, z=-0.992$ and $p=0.32$ ). In addition, Chi squared tests indicated no significant difference between the patients and controls regarding gender $\left(\chi^{2}=0.014, p=0.90\right)$ and education $\left(\chi^{2}=0.300, p=0.58\right)$.

\section{Learning style distribution}

The A-LSI yielded the following distribution of learning styles: 4 doers, 54 observers, 2 deciders and 39 thinkers. A similar distribution was found for the control group $(3,28,0$ and 11, 
respectively). For the patient group, there was a significant association between learning style (observer, thinker) and education (low, high) $\left(\chi^{2}=9.75, p=0.002\right)$ with a higher percentage of high educated patients in the thinker group (56.4\%) than in the observer group (24\%). This association was not found in the control group $\left(\chi^{2}=0.14, p=0.71\right)$.

\section{Internal validity of the A-LSI}

Internal validity of the A-LSI was investigated by means of Spearman correlations between A-LSI learning modes and dimensions (Table 2). For 29 patients we could only trace back their overall learning style and not the scores for learning modes and dimensions. For the remaining 70 patients, scores for learning modes and dimensions were used to evaluate internal validity of the A-LSI. First, we evaluated whether the two dimensions, prehension and transformation, are independent. As hypothesized, there was no significant association between the two dimensions and no significant association between dimensions and crossdimensional learning modes ( $\mathrm{CE}, \mathrm{AC}$ and $\mathrm{AE}-\mathrm{RO}$; $\mathrm{AE}, \mathrm{RO}$ and $\mathrm{AC}-\mathrm{CE})$. These results provide support for two independent dimensions. Second, we determined whether the two dimensions are bipolar. In contrast to our hypothesis, the within-dimension learning modes for the prehension dimension ( $\mathrm{AC}$ and $\mathrm{CE}$ ) were not significantly associated. The two learning modes belonging to

Table 1. Characteristics of the study sample.

\begin{tabular}{|c|c|c|}
\hline & $\begin{array}{l}\text { ABI group } \\
(n=99)\end{array}$ & $\begin{array}{c}\text { Control group } \\
(n=42)\end{array}$ \\
\hline Gender, female, \% $(n)$ & $39.4 \%(39)$ & $40.5 \%(17)$ \\
\hline Mean age in years (SD) & $55.9(14.2)$ & $54.5(12.8)$ \\
\hline Range & $18-84$ & $30-85$ \\
\hline High education, $\%(n)^{\mathrm{a}}$ & $37.9 \%(36)^{\mathrm{b}}$ & $42.9 \%(18)$ \\
\hline \multicolumn{3}{|l|}{ Diagnosis, \% (n) } \\
\hline Ischaemic stroke & $53.5 \%(53)$ & \\
\hline Haemorrhagic stroke & $17.2 \%(17)$ & \\
\hline Subarachnoid haemorrhage & $7.1 \%(7)$ & \\
\hline Post-anoxic brain damage & $5.1 \%(5)$ & \\
\hline Traumatic brain injury & $13.1 \%(13)$ & \\
\hline Brain abscess & $1.0 \%(1)$ & \\
\hline Brain tumour & $2.0 \%(2)$ & \\
\hline Friedreich ataxia & $1.0 \%(1)$ & \\
\hline MMSE, mean (SD) & & $29.6(0.7)$ \\
\hline \multicolumn{3}{|l|}{ Barthel Index } \\
\hline Independent (20), \% ( $n)$ & $19.2 \%(19)$ & \\
\hline Mild disability (15-19), \% (n) & $39.3 \%(39)$ & \\
\hline Moderate/severe disability $(0-14), \%(n)$ & $41.4 \%(41)$ & \\
\hline USER cognition, mean (SD) & $40.1(8.9)^{\mathrm{c}}$ & \\
\hline
\end{tabular}

the transformation dimension (AE and $\mathrm{RO}$ ) did show a significant negative association $(r=-0.35, p=0.003)$. Furthermore, we hypothesized that the cross-dimensional learning modes were unrelated. One out of four correlations for cross-dimensional learning modes was significant (CE and AE: $r=-0.40$, $p=0.001)$. This correlation was comparable to the significant within-dimension learning modes (AE and RO: $r=-0.35$, $p=0.003)$. These results suggest that only the transformation dimension is bipolar.

\section{Content validity of the A-LSI}

Content validity of the A-LSI was assessed by asking patients and controls whether they recognized themselves in the assessed learning style. In total, 58\% (11 out of 19) of patients recognized themselves in the assessed learning style. Eight patients did not recognize themselves in the assessed learning style of which one person strongly disagreed, two persons were neutral and five persons slightly agreed with the assessed learning style. For the control group, $71 \%$ (27 out of 38) of controls showed a positive recognition of their learning style as indicated by the A-LSI (Table 3). Of the remaining 11 healthy controls, two persons disagreed with the assessed learning style, one person was neutral and eight persons slightly agreed with the A-LSI learning style. There was no significant difference between the two groups regarding the number of positive recognitions $\left(\chi^{2}=0.99\right.$, $p=0.32$ ).

\section{Feasibility of the A-LSI and learning style in general}

We interviewed three psychologists, three physical therapists, three occupational therapists and three cognition therapists.

\section{Implementing learning style in rehabilitation}

All interviewees were generally positive about the implementation of learning style in rehabilitation; though, the majority considered it difficult to implement learning style into clinical practice. The physical and occupational therapists reported that they mainly rely on their experience and clinical observations

Table 3. Recognition of the A-LSI learning style in a patient and control subgroup.

\begin{tabular}{lrcrrr}
\hline & \multicolumn{2}{c}{ ABI patients $(n=19)$} & & \multicolumn{2}{c}{ Controls $(n=38)$} \\
\cline { 2 - 3 } \cline { 5 - 6 } Learning style & $n$ & $\begin{array}{c}\text { Positive } \\
\text { recognition, } n\end{array}$ & & $\begin{array}{c}\text { Positive } \\
\text { recognition, } n\end{array}$ \\
\hline Doer & 1 & 1 & 1 & 1 \\
Observer & 12 & 5 & & 26 & 20 \\
Decider & 0 & - & & 0 & - \\
Thinker & 6 & 5 & & 11 & 6 \\
\hline
\end{tabular}

Table 2. Spearman correlations between A-LSI modes and dimensions in the patient group $(n=70)$.

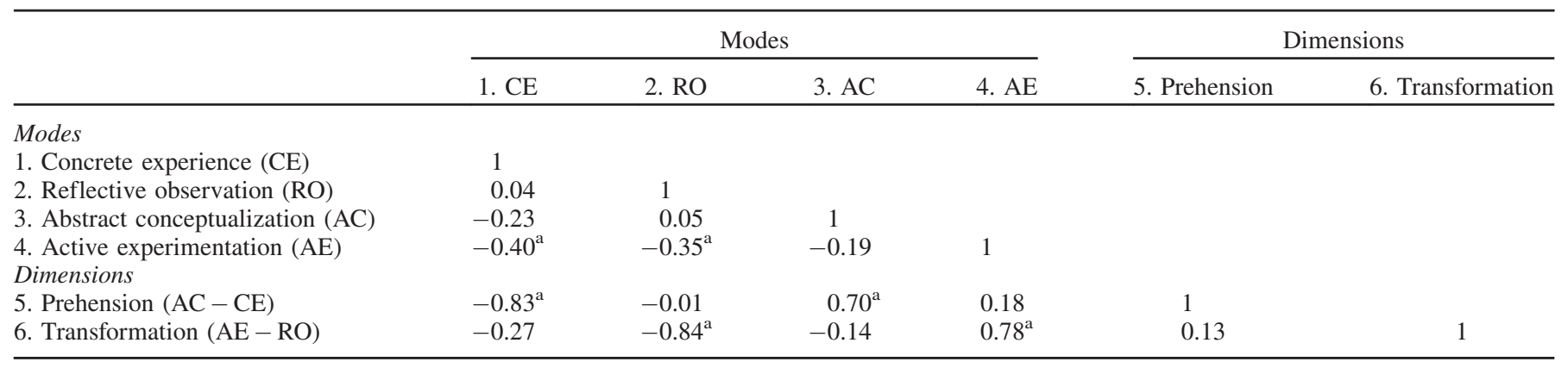

${ }^{\mathrm{a}}$ Significant after Bonferroni correction $(p \leq 0.003)$. 
during therapy when using the concept of learning style instead of using an instrument. An occupational and a physical therapist mentioned that it is hard to consciously integrate learning style during therapy; this requires additional preparation time and is therefore not always used consequently. Learning style is coming back into consideration when therapy stagnates or in the case of problems during therapy. Furthermore, some interviewees considered learning style to be a fixed trait that is more or less the same over tasks. Others suggested a situation-specific learning style and therefore make minimal use of the assessed learning style and accompanying advice.

\section{Learning style and cognition}

According to a psychologist, learning style should be put into perspective with the cognitive profile and personality of the patient. In the case of severe cognitive impairments, learning style is of less importance. An occupational therapist argued that it is possible to use learning style in these patients but on a lower level, for instance by giving more assistance. According to one of the psychologists, it is useful to evaluate difficulties from a learning style perspective. For instance, repetitive failing attempts at executing a certain task might be interpreted as impaired awareness of deficits while seen from a learning style perspective this could also have been caused by a trial-and-error learning approach.

\section{Positive aspects of the A-LSI}

Most consider the A-LSI a concise and easy to use instrument. The items are concrete and imaginable. According to one of the cognition therapists, the total of nine items is the maximum number of items that most individuals with $\mathrm{ABI}$ are able to complete. Another cognition therapist said that patients with ABI are generally positive about learning style assessment and consider it to be important. An occupational therapist, a psychologist and a cognition therapist mentioned that the A-LSI provides an explicit learning framework which can be used at the start of rehabilitation instead of having to discover the patient's learning preferences during treatment. According to one of the cognition therapists, the A-LSI makes it possible to adapt to the patient's preferences instead of the other way around which can consequently lead to a more unified, efficient approach of the entire rehabilitation team.

\section{Negative aspects of the A-LSI}

The majority of interviewees mentioned that completing the A-LSI requires a relatively high level of cognitive functioning (e.g. language comprehension, conceptualization and executive functioning) and is not suitable for patients with severe aphasia. According to two cognition therapists, most patients were able to rate the most and least favourite answer, but experience difficulties with rating their second and third choice.

Concerning the items, the cognition therapists mentioned that these were not always well comprehended. Moreover, some questions caused reactions linked to the ongoing phase of acceptance. For instance, the question about learning how to sail a boat sometimes caused the individual's reaction "I will never be able to learn how to sail anymore'.

Two psychologists, an occupational therapist and a physical therapist expressed their doubts about the practical use in rehabilitation and since it was originally developed for educational purposes it might be inappropriate for use in rehabilitation. In addition, a physical and an occupational therapist mentioned that the learning style assessed with the A-LSI was not always in accordance with the learning style that was seen during observation. In contrast, two of the physical therapist mentioned that the reported learning style was always in accordance with the observed learning style.

\section{Suggestions for improvement of the A-LSI and for using learning} style in rehabilitation

Concerning the content of the items several suggestions were postulated. First, a psychologist and cognition therapist suggested using items that address general activities that are important for rehabilitation. For instance, "during therapy you can choose the method of instruction, what do you choose?'. Every discipline could provide a certain skill that is important for their therapy. Second, an occupational therapist mentioned that items could focus more on the individual person which would consequently lead to a unique, personified A-LSI for each individual. Furthermore, there was a desire to make the A-LSI more accessible for patients with aphasia. A suggestion of a cognition therapist to this end was to use pictograms or to interview the primary caregiver of the patient.

Several interviewees proposed that a patient's learning style cannot be based on a questionnaire alone. They suggested to add a practical task. Herein, it could be examined which learning style features can be seen during observation of that task. In addition, a physical therapist suggested that each discipline should observe learning style, these observations could be combined into one multidisciplinary advice. In addition, an occupational and a physical therapist suggested that the learning process of each patient should be evaluated more explicitly during multidisciplinary team meetings in order to exchange and increase knowledge about learning style.

\section{Discussion}

In this study we evaluated the validity and feasibility of a learning style instrument, the A-LSI, in inpatients in ABI rehabilitation. The results of this exploratory study indicated that rehabilitation professionals were generally positive about learning style assessment in rehabilitation. This study, however, raises doubts about the validity and feasibility of the A-LSI for this population.

A remarkable finding was that the vast majority of patients and controls had an observer or thinker learning style. This skewed distribution may be explained by the insufficient internal validity of the A-LSI. That is, the A-LSI contains two independent dimensions of learning but only the transformation dimension turned out to be bipolar.

Despite the insufficient internal validity of the A-LSI, the majority of patients and controls had some degree of recognition of the A-LSI learning style. In total, $84 \%$ of patients and $91 \%$ of healthy controls reported that they slightly agreed, agreed, or strongly agreed with the assessed learning style. This may be explained by the fact that most persons use all four modes of learning to some extent. For instance, a person with a thinker learning style cannot solely depend on reflection and observation when learning how to sail a boat. This person also needs to step into the sailboat and gain concrete experience with sailing. Hence, persons may recognize themselves in several aspects of each learning style.

The qualitative evaluation revealed that rehabilitation professionals mainly used learning style in the case of problems during therapy while, preferably, learning style should be used to prevent problems and to guide therapy. Therefore, learning style should be assessed directly at the start of rehabilitation as part of the diagnostic procedures. In our sample, the A-LSI was assessed, on average, 40 days after admission to the rehabilitation centre. Meanwhile, therapists have already developed their own teaching approach.

To our knowledge, there is only one previous study that investigated perceptions on learning style assessment in 
individuals with a neurological condition [20]. That study investigated paediatric physical therapists and physical educators' perceptions on classifying learning styles in children and adolescents with cerebral palsy. In agreement with our study, the majority of interviewees were generally positive about learning style classification. Furthermore, the authors concluded that Kolb's LSI provided no useful basis for classifying learning styles for that population due to, among others, its difficult administration procedure and unsuitability in the case of low levels of cognition. This is in accordance with our results.

Several limitations of this study should be noted. The A-LSI was originally developed for students; information concerning the development of the A-LSI was not available. It remains to be seen whether it is possible and sensible to utilize an instrument that was originally developed for use in education. However, given the exploratory nature of this study, we considered it important to start with evaluating an existing learning style instrument to gain familiarity and experience with learning style in rehabilitation before developing a new instrument for rehabilitation.

The A-LSI relies on self-report while many patients with ABI have impaired awareness of deficits and difficulty with selfmonitoring. Consequently, the validity of the responses can be doubted. A previous study that used different measures to assess learning style found no significant association between a selfreport instrument and a performance-based instrument [21]. Future studies are needed to determine the validity of self-report measures of learning style.

Another limitation of this study is that we studied a convenience sample of patients with ABI which caused a rather heterogeneous group as regards diagnosis. However, for the current study we were interested in all patients with ABI, naturally occurring in a rehabilitation setting, irrespective of diagnosis. More research is needed to determine whether there is an association between learning style and diagnosis.

Further research into learning style is recommended to increase our understanding of learning style post-ABI and the added value for rehabilitation. Longitudinal studies are needed to, for instance, determine whether learning styles change during the rehabilitation process and to assess whether learning style is a predictor of rehabilitation outcome.

In conclusion, rehabilitation professionals considered learning style to be relevant for rehabilitation but found it difficult to implement in clinical practice. Even though the A-LSI might not be appropriate for an ABI population, this exploratory study provides a basis for further research into the concept of learning style. We recommend that future studies consider alternatives to self-report questionnaires such as behavioural observations or proxy questionnaires. We furthermore recommend that learning style should be assessed directly at the start of rehabilitation as part of the diagnostic procedures. For now, we believe it is important to acquaint rehabilitation professionals with the concept of learning style so that they are aware of the fact that their own learning style might not be the same as the patient they are treating and that they learn how to implement learning style into clinical practice.

\section{Acknowledgements}

Special thanks to Lisette Meijer, Klaartje Verhoeven, Corine Werkhoven, Joke Heins, Bianca van Oossanen and Roos Sevat for providing the files and the interviewees for expressing their critical opinion.

\section{Declaration of interest}

This project is part of the research programme Cognitive Rehabilitation which is funded by the National Initiative on Brain and Cognition in the
Netherlands (NWO number 056-11-014). The authors declare that they have no conflicts of interest.

\section{References}

1. Wade DT. Describing rehabilitation interventions. Clin Rehabil 2005;19:811-18.

2. Smits DW, Verschuren O, Ketelaar M, van Heugten CM. Introducing the concept of learning styles in rehabilitation. J Rehabil Med 2010;42:697-9.

3. Cassidy S. Learning styles: an overview of theories, models, and measures. Educ Psychol 2004;24:419-44.

4. Doorn van K, McManus F, Yiend J. An analysis of matching cognitive-behavior therapy techniques to learning styles. J Behav Ther Exp Psychiatry 2012;43:1039-44.

5. Koonce TY, Gluse NB, Storrow AB. A pilot study to evaluate learning style-tailored information prescriptions for hypertensive emergency department patients. J Med Libr Assoc 2011;99: $280-9$.

6. Fujii DE. Kolb's learning styles and potential cognitive remediations of brain-injured individuals: an exploratory factor analysis study. Prof Psychol Res Pract 1996;27:266-71.

7. Denby F, Harvey RL. An educational intervention for stroke rehabilitation patients and their families: healthy living after stroke. Top Stroke Rehabil 2003;9:34-45.

8. Parente R, Stapleton MC, Wheatley CJ. Practical strategies for vocational reentry after traumatic brain injury. J Head Trauma Rehabil 1991;6:33-45.

9. Boosman H, Visser-Meily JMA, Post MWM, et al. Exploring the relation between learning style and cognitive impairment in patients with acquired brain injury. Neuropsychol Rehabil 2012;22:26-39.

10. Schwartz SM. Adults with traumatic brain injury: three case studies of cognitive rehabilitation in the home setting. Am J Occup Ther 1995;49:655-67.

11. Hochstenbach J, Mulder T, van Limbeek J, et al. Cognitive decline following stroke: a comprehensive study of cognitive decline following stroke. J Clin Exp Neuropsychol 1998;20:503-17.

12. Hellawel DJ, Taylor RT, Pentland B. Cognitive and psychosocial outcome following moderate or severe traumatic brain injury. Brain Inj 1999;13:489-504.

13. Al-Khindi T, Macdonald L, Schweizer TA. Cognitive and functional outcome after aneurysmal subarachnoid hemorrhage. Stroke 2010;41:519-36.

14. Akkerman B. Leerstijlentest Kolb/Akkerman. 2003. Available from: http://www.brandwonden.nl/download/146 [last accessed 11 Oct 2010].

15. Kolb AY, Kolb DA. The Kolb Learning Style Inventory Version 3.1, 2005 Technical Specifications. Available from: http:// www.learningfromexperience.com [last accessed 9 Sep 2010].

16. Kolb DA, Boyatzis RE, Mainemelis C. Experiential learning theory: previous research and new directions. 2000. Available from: http:// www.d.umn.edu/ kgilbert/educ5165-731/Readings/experientiallearning-theory.pdf [last accessed 14 Nov 2012].

17. Folstein MF, Folstein SE, McHugh PR. "Mini-mental state". A practical method for grading the cognitive state of patients for the clinician. J Psychiatr Res 1975;12:189-98.

18. Wade DT, Collin C. The Barthel ADL Index: a standard measure of physical disability? Int Disabil Stud 1988;10:64-7.

19. Post MWM, van de Port IG, Kap B, Berdenis van Berlekom SH. Development and validation of the Utrecht Scale for Evaluation of Clinical Rehabilitation (USER). Clin Rehabil 2009;23:907-17.

20. Smits DW, Verschuren O, Gorter JW, et al. Perceptions of pediatric physical therapists and physical educators on classifying learning styles of children and adolescents with cerebral palsy. Phys Occup Ther Pediatr 2011;31:403-12.

21. Reed BJ. Assessment of preferred learning styles: self-report versus performance based approach. Vocational Eval Work Adjustment Bull 1996;29:119-24. 


\section{Appendix}

Table A1. Translated items of the A-LSI ${ }^{\mathrm{a}}$.

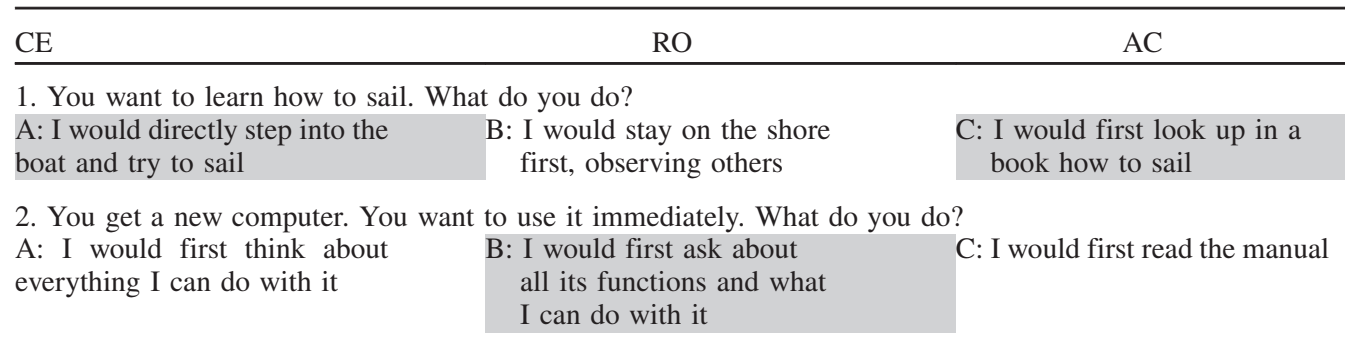

3. You put together a piece of furniture. What do you do?
A: I would first verify what I
have to do and determine the
best way to do it
B: I would read the manual completely and take a close look at the building plan
C: I would first check what I can use the piece of furni- ture for

4. You hear a story about an exciting event and you want to tell the story at home. What do you do?
A: I would imagine that the
B: I love what I am hearing and
I want to witness the excit-
ing event for myself
C: I first want to know whether the story is correct
pening and that I'm present

5. You are going on holiday. You choose out of two countries. What do you do?
A: I would imagine what I B: I would not think too long.

could do in these countries. I You have to make the best of

find it hard to choose
C: I would try to get to know as much as possible about the countries. Afterwards I would decide

6. You are going to buy a new bicycle. What do you do?

A: I would think about where I could go with the bicycle and how much fun it would be

B: I would want to know exactly the specifications, which one is the best and the prices

7. You have an exam. What do you do?

A: I would only learn what I B: I would try to understand the need to know for the exam learning material

\section{C: I would want to try the new bicycle immediately

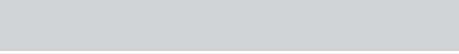

C: I would write down the most important things

C: I would want to know exactly what someone has to do in the company and how the company works
D: I would ask someone to demonstrate it

D: I would try out everything immediately

D: I would immediately start putting the piece of furniture together

D: I would just repeat the story

D: I would consider what would be the best for me. I am a quick decider

D. I would consider which bicycle is most suitable for me

D: I learn, just because I need to

D: I would go to work and then experience whether I like it or not exactly how hard I have to work and how much money I earn
9. You are attending a course and you can decide about the way of teaching. What do you do?
$\begin{array}{lll}\text { A: I would want the professor } & \text { B: I would want to work on } & \text { C: I would want to receive }\end{array}$ B: I would want to work on to tell stories
D: I would like to know why I have to do certain assignments

${ }^{\mathrm{a}}$ The grey-coloured answers are not included in the sum-scores. 